\title{
Effect of dietary olive leaves and rosemary on microbial growth and lipid oxidation of turkey breast during refrigerated storage
}

\author{
A. Govaris ${ }^{1}$, E. Botsoglou ${ }^{1}$, A. Moulas ${ }^{2}$ and N. Botsoglou ${ }^{3 \#}$ \\ ${ }^{1}$ Laboratory of Hygiene of Foods of Animal Origin, School of Veterinary Medicine, \\ University of Thessaly, 43100 Karditsa, Greece \\ ${ }^{2}$ Laboratory of Biochemistry, Department of Animal Production, Technological Education \\ Institute TEI, 41110 Larissa, Greece \\ ${ }^{3}$ Laboratory of Animal Nutrition, School of Veterinary Medicine, Aristotle University, \\ 54124 Thessaloniki, Greece
}

\begin{abstract}
Forty turkeys were allocated to five groups of eight birds each. One (control) was fed a basal diet while the others were fed diets supplemented with either olive leaves at $10 \mathrm{~g} / \mathrm{kg}$, rosemary at $10 \mathrm{~g} / \mathrm{kg}$, $\alpha$-tocopheryl acetate at 150 or at $300 \mathrm{mg} / \mathrm{kg}$ feed. Following slaughter, fillets from the breasts of the birds were stored at $4{ }^{\circ} \mathrm{C}$ in the dark for 12 days and their lipid oxidation and microbial growth rate were monitored. Results showed that dietary olive leaves were more effective in inhibiting lipid oxidation of the breast fillets compared to rosemary, but inferior to the dietary supplementation of $300 \mathrm{mg}$ a-tocopheryl acetate $/ \mathrm{kg}$. In turn, lipid oxidation was more effectively inhibited when the birds received $\alpha$-tocopheryl acetate supplementation at $150 \mathrm{mg} / \mathrm{kg}$ compared to when the birds received no suppelementation, but inferior to rosemary supplementation. Total viable counts, lactic acid bacteria, Enterobacteriaceae and psychrotrophic bacterial counts were all increased in breast fillets of all groups throughout refrigerated storage. Diet supplementation with a basal level of $\alpha$-tocopheryl acetate had no effect on the bacterial counts recorded in the control group, but diet supplementation with olive leaves or rosemary resulted in a decrease in all bacterial counts from day 2 of storage and thereafter. During this period olive leaves were more effective in inhibiting bacterial growth than rosemary.
\end{abstract}

Keywords: Antioxidant additives, $\alpha$-tocopherol, turkey meat, herbs, spices, meat quality

${ }^{\#}$ Corresponding author. E-mail: bots@vet.auth.gr

\section{Introduction}

Lipid oxidation is primarily initiated in the highly unsaturated fatty acid fraction of membrane phospholipids, leading to production of hydroperoxides, which are susceptible to further oxidation or decomposition to secondary reaction products that may adversely affect the overall quality of meat (Vercellotti et al., 1992). Poultry muscle tissues are particularly susceptible to lipid oxidation during refrigerated storage due to their relatively high content in polyunsaturated fatty acids. The susceptibility to oxidative deterioration is higher for turkey compared to chicken tissues, although tissues from both species contain comparable fatty acid compositions. This is primarily due to a weaker ability of turkeys to accumulate dietary tocopherol in their tissues (Botsoglou et al., 2003; Papageorgiou et al., 2003). Dietary administration of $\alpha$-tocopherol allows its incorporation into subcellular membranes where it can effectively inhibit oxidative reactions at their localized sites (Packer \& Kagan, 1993).

In the last few years oxidative deterioration of muscle tissues is of increasing concern since novel feeding strategies have raised the levels of polyunsaturated fatty acids in the so-called functional meat. However, increasing levels of polyunsaturated fatty acids in tissues lead to faster lipid oxidation, with a consequent quality loss and lower consumer acceptability. To delay lipid oxidation, various additives especially of synthetic origin, are often added to meat products. However, consumers and health authorities increasingly dictate that the use of synthetic food additives should be phased out and, where possible, only natural products should be used. Hence, alternatives from natural sources with potential antioxidant activity are investigated.

In the search for natural antioxidant additives, much attention has been directed to herbs and spices. Rosemary, in particular, has been found to be a promising dietary supplement that contains a variety of 
compounds including carnosol, carnosic acid, rosmanol, 7-methyl-epirosmanol, isorosmanol, rosmadial, caffeic acid, 1,8 cineol, camphor and $\alpha$-pinene, which have substantial in vitro antimicrobial and antioxidant activities (Barrata et al., 1998; Ibanez et al., 2003). Rosemary is a spice obtained by drying the leaves and flowers of the plant, Rosmarinus officinalis. In a study assessing the antioxidant properties of some spices frequently used in the Mediterranean diet, rosemary was found to be the most effective scavenger of peroxyl radicals in an ox brain phospholipid system. It was compared with oregano, annatto, paprika, cumin, saffron and common synthetic food additives (Martinez-Tome et al., 2001). Carnosic acid, the most active antioxidant constituent of rosemary, has shown in in vitro studies an antioxidant activity approximately three times higher than carnosol and seven times higher than that of the common synthetic additives, butylated hydroxytoluene and butylated hydroxyanisole (Cuvelier et al., 1996; Richheimer et al., 1996; Offord et al., 1997). In addition, 1,8 cineol, $\alpha$-pinene and camphor have been identified as most active antimicrobial components (Pandit \& Shelef, 1994; Barrata et al., 1998). Obviously, due to its high content of bioactive components, ground rosemary has proven in in vivo studies to be an efficient dietary supplement that could inhibit microbial growth and lipid oxidation in turkey tissues during refrigerated storage (Botsoglou et al., 2007; Govaris et al., 2007).

Unlike rosemary that has to be cultivated before processing, there are several other potential sources of antioxidant phytochemicals such as the leaves of the olive tree (Olea europea L.), which are readily available and require minimal processing. Olive leaves, one of the by-products of olive tree farming, can be found in large quantities in the olive oil industries and can also accumulate in large volumes on farms during the pruning of the trees. Olive leaves are a good source of several antioxidants including oleuropeoside compounds such as oleuropein and verbascoside, and flavonoid compounds such as luteolin, luteolin-7glucoside, apigenin-7-glucoside, diosmetin, diosmetin-7-glucoside, rutin and catechin, and simple phenolic compounds such as tyrosol, hydroxytyrosol, vanillin, vanillic acid and caffeic acid. Oleuropein, the most prominent compound, may reach concentrations of $60-90 \mathrm{mg} / \mathrm{g}$ dried leaves (Ryan et al., 2002). Most of these phenolic compounds have been shown to possess substantial antimicrobial and antioxidant activities in vitro (Kubo et al., 1995; Markin et al., 2002), while other non-phenolic components such as aldehydes have also been studied for their antimicrobial properties (Kubo et al., 1995; Bisignano et al., 2001). However, in vivo investigations on the antioxidant and antimicrobial activities of olive leaves as a dietary supplement to food producing animals have not been conducted.

Use of nutritional strategies such as the incorporation of suitable phytochemicals to improve the oxidative stability of animal products can extend the shelf life and increase the acceptability of muscle food during retail display. However, a major concern with extending the shelf life of muscle food is associated with the extent and type of microbial growth that might occur during the additional time of product acceptability. Delayed lipid oxidation caused by the use of supplemental dietary antioxidants may mask microbial growth without warning consumers because some of the initial signs of meat spoilage such as offflavours or discoloration may be hidden due to decreased lipid oxidation, although concentrations of bacteria might be high. This fact may be an adverse factor to the health of consumers of such meats. The present study was designed to evaluate and compare the inhibitory potentials of feed supplementation with olive leaves, rosemary and/or $\alpha$-tocopheryl acetate on microbial growth and lipid oxidation of turkey breast fillets during refrigerated storage.

\section{Materials and Methods}

Forty female turkeys (black local breed), eight weeks old, were allocated to five experimental groups in this study. The birds were allowed to acclimatize for a period of two weeks. During the acclimatization period they were fed ad libitum a commercial maize-soyabean based turkey diet supplemented with $10 \mathrm{mg}$ $\alpha$-tocopheryl acetate $/ \mathrm{kg}$. The ingredients and the composition of the commercial diet are presented in Table 1. The lighting programme was set at 60 watt $/ 10 \mathrm{~m}^{2}$ during the first week with continuous light thereafter, and the temperature was set at $21{ }^{\circ} \mathrm{C}$. The humidity was $65-75 \%$, and conventional breeding and management procedures were employed throughout the experiment. Birds were cared for in accordance with the guide for the care and use of laboratory animals (Committee on Care and Use of Laboratory Animals, 1996).

At the end of the acclimatization period, feeding of the commercial diet was discontinued to all but one of the groups. The birds within this control group (CONT) were fed the commercial diet for a further 
Table 1 Nutrients composition of commercial diet for turkeys

\begin{tabular}{lclc}
\hline Ingredients & $\begin{array}{c}\text { Composition } \\
(\mathrm{g} / \mathrm{kg})\end{array}$ & Ingredients & $\begin{array}{c}\text { Composition } \\
(\mathrm{g} / \mathrm{kg})\end{array}$ \\
\hline Maize grains & 484.5 & Biolysine & 2.5 \\
Soyabean meal & 320.0 & Choline chloride & 0.2 \\
Soyabean oil & 18.0 & Limestone pulverized & 17.5 \\
Herring meal & 20.0 & Monocalcium phosphate & 14.0 \\
Corn gluten meal & 22.5 & Sodium chloride, iodized & 2.7 \\
Wheat bran & 40.0 & Natuphos (phytase $)$ & 0.1 \\
Corn gluten feed & 40.0 & Vitamin premix & 1.0 \\
Yeast & 15.0 & Trace-mineral premix & 1.0 \\
DL-methionine & 1.0 & &
\end{tabular}

\footnotetext{
${ }^{\text {a }}$ Content per kg feed: 10,000 IU all-trans retinol acetate; 5,000 IU cholecalciferol; $30 \mathrm{mg} \alpha$-tocopheryl acetate; $6 \mathrm{mg}$ menadione sodium bisulphite; $5 \mathrm{mg}$ thiamine hydrochloride; $10 \mathrm{mg}$ riboflavin; $10 \mathrm{mg}$ pyridoxine hydrochloride; $0.02 \mathrm{mg}$ cyanocobalamine; $85 \mathrm{mg}$ niacin; $25 \mathrm{mg}$ pantothenic acid; $2 \mathrm{mg}$ folic acid; $0.25 \mathrm{mg}$ biotin; $10 \mathrm{mg}$ ascorbic acid.

${ }^{\mathrm{b}}$ Content per kg feed: $100 \mathrm{mg} \mathrm{Zn;} 120 \mathrm{mg} \mathrm{Mn} ; 20 \mathrm{mg} \mathrm{Fe} ; 20 \mathrm{mg} \mathrm{Cu} ; 0.2 \mathrm{mg} \mathrm{Co} ; 1 \mathrm{mg} \mathrm{I} ; 0.3 \mathrm{mg} \mathrm{Se}$.
}

four weeks. The experimental diets fed to the remaining four groups were based on the same commercial diet, but supplemented with $10 \mathrm{~g}$ olive leaves/kg (OLE), $10 \mathrm{~g}$ rosemary/kg (ROS), $150 \mathrm{mg} \alpha$-tocopheryl acetate $/ \mathrm{kg}$ (T150) or $300 \mathrm{mg} \alpha$-tocopheryl acetate $/ \mathrm{kg}$ (T300) of feed. Supplementation of the commercial diet with olive leaves or rosemary was achieved at the expense of wheat bran. The turkeys were fed the experimental diets for four weeks.

Olive leaves were collected from Olea europaea L. trees not treated with any chemical in the last six months, and rosemary consisted of flower leaves of cultivated Rosmarinus officinalis plants. Collected leaves were first air-oven dried at $45{ }^{\circ} \mathrm{C}$ for three consecutive days and then ground to pass a $2 \mathrm{~mm}$ screen. Proximate analysis of the dry olive leaves showed that they contained $70 \mathrm{~g}$ moisture, $85 \mathrm{~g}$ crude protein, $45 \mathrm{~g}$ fat, $165 \mathrm{~g}$ crude fibre, $172 \mathrm{~g}$ lignin and $51 \mathrm{~g}$ ash $/ \mathrm{kg}$. Steam distillation of the collected rosemary using a Clevenger type apparatus resulted in an essential oil yield of $1.0 \mathrm{~mL} / 100 \mathrm{~g}$. Analysis of this essential oil by gas chromatography (ThermoQuest Trace GC, Italy) on a fused silica column, Durabond DB-1, $60 \mathrm{~m} \times 0.25$ mm i.d., showed the major components were eucalyptol at $392 \mathrm{~g} / \mathrm{kg}$, vorneol at $131 \mathrm{~g} / \mathrm{kg}$ and a-pinene at 46 g/kg. $\alpha$-Tocopheryl acetate was obtained from Roche Products Ltd. (Hertfordshire, UK).

At 14 weeks of age the turkeys were weighed, slaughtered and their carcasses were trimmed for breast fillets by removing the skin, bones and connective tissues. Following trimming, the breast fillets from each bird were individually divided into two. One group was used for microbiological analysis and the other for oxidative stability studies

The concentrations of total phenolics in olive leaves and rosemary were determined using the FolinCiocalteau reagent according to a slightly modified procedure (Singleton et al., 1999). In this analysis, the sample $(0.5 \mathrm{~g})$ was transferred to a $50 \mathrm{~mL}$ centrifugal tube where $25 \mathrm{~mL}$ of $80 \%$ aqueous methanol was added. The mixture was homogenized (Ultra-Turrax homogenizer) at high speed $(20500 \mathrm{rpm})$ for $30 \mathrm{~s}$ and the homogenate was filtered. Filtrate aliquots of $0.05 \mathrm{~mL}$ were transferred to $15 \mathrm{~mL}$ tubes and mixed (Vortex apparatus, Scientific Industries, Inc., Model K-550-GE) with $6.45 \mathrm{~mL}$ distilled water and $0.5 \mathrm{~mL}$ of the Folin-Ciocalteau reagent (Sigma-Aldrich, $\mathrm{GmbH}$, Sternheim, Germany). The mixture was allowed to stand for $3 \mathrm{~min}$ and, after the addition of $3 \mathrm{~mL}$ of a $7.5 \%$ aqueous $\mathrm{Na}_{2} \mathrm{CO}_{3}$ solution, was allowed to incubate for an additional $60 \mathrm{~min}$ at room temperature. Following incubation, the mixture was centrifuged at $2000 \mathrm{~g}$ for $5 \mathrm{~min}$. The absorbance of the supernatant was measured at $760 \mathrm{~nm}$ (Spectrophotometer Shimadzu, Model UV-160A, Tokyo, Japan).

Since the concentration of total phenolics was calculated in gallic acid equivalents per gram of sample, the calibration curve was constructed using gallic acid as a reference standard. This standard solution was prepared by weighing $20 \mathrm{mg}$ of gallic acid into a $50 \mathrm{~mL}$ volumetric flask and diluted to volume with $80 \%$ aqueous methanol. Volumes of $0.05-2.5 \mathrm{~mL}$ from this solution that corresponded to $20-100 \mu \mathrm{g}$ of gallic acid were placed in $15 \mathrm{~mL}$ tubes, diluted to $6.5 \mathrm{~mL}$ with water, mixed with $0.5 \mathrm{~mL}$ of the Folin-Ciocalteau 
reagent and $3 \mathrm{~mL}$ of $7.5 \% \mathrm{Na}_{2} \mathrm{CO}_{3}$. Their absorbance was measured at $760 \mathrm{~nm}$. Total phenolics were calculated in mg of gallic acid equivalents per gram by referring to slope and intercept data of the computed least-squares fit of this standard calibration curve.

For the determination of the antioxidant capacity of olive leaves and rosemary, an improved version (Re et al., 1999) of the trolox equivalent antioxidant capacity (TEAC) assay applicable to both lipophilic and hydrophilic antioxidants was applied. This improved version involves direct production of the blue/green ABTS radical cation chromophore through the reaction between a $7 \mathrm{mM}$ aqueous solution of 2,2;-azinobis(3ethylbenzothiazoline-6-sulfonic acid diammonium salt (ABTS) obtained from Aldrich Chemical Co (Gillingham, Dorset, U.K.) and potassium persulphate with $2.45 \mathrm{mM}$ (final concentration) aqueous solution of potassium persulphate in the dark for $12-16 \mathrm{~h}$, at ambient temperature. The radical cation was stable in this form for more than two days when stored in the dark at room temperature. Addition of antioxidants to the preformed radical cation causes decolorization at an extent which depends on the antioxidant activity, and calculated relative to the reactivity of 6-hydroxy-2,5,7,8-tetramethylchroman-2-carboxylic acid (Trolox) as a standard, obtained from Aldrich Chemical Co, Gillingham, Dorset, UK. For the determination of the TEAC value, the ABTS radical cation solution was further diluted with methanol to an absorbance of 0.7 at $734 \mathrm{~nm}$. Samples $(0.5 \mathrm{~g})$ were placed in $50 \mathrm{~mL}$ centrifugal tubes and $25 \mathrm{~mL}$ of $80 \%$ aqueous methanol were added. The mixtures were homogenized at high speed $(20500 \mathrm{rpm})$ for $1 \mathrm{~min}$ and the homogenates were filtered. The aqueous methanol extracts were further diluted with methanol such that, after addition of a 50 $\mu \mathrm{L}$ aliquot to $2.45 \mathrm{~mL}$ of the diluted ABTS radical cation solution, they resulted in inhibition of the blank absorbance between $20-80 \%$. Absorbance readings were taken at $734 \mathrm{~nm}$ exactly 1 min after initial mixing. Appropriate solvent blanks were run in each assay. In addition, a calibration curve was generated by running a series of Trolox standards (range of final concentrations, $0-15 \mu \mathrm{M}$ ) in methanol. The recorded percentage inhibition values of absorbance at $734 \mathrm{~nm} v s$. the corresponding mass of the analyte were plotted, and the slope, intercept and least squared fit of standard curve were computed. TEAC values of samples (micromoles of Trolox equivalents per gram) were realized by reference to the standard curve, and multiplying with appropriate dilution factor.

To access the effect of the dietary treatments on the oxidative stability of turkey breast fillets during refrigerated storage, samples were sliced $0.5 \mathrm{~cm}$ thick, placed in open sterile polypropylene bags and stored at $4{ }^{\circ} \mathrm{C}$ in the dark. Oxidative changes were monitored on the basis of malondialdehyde (MDA) formed at day 0 and at 2-d intervals for up to 12 days of storage. MDA, the compound used as an index of lipid peroxidation, was determined by a selective third-order derivative spectrophotometric method (Botsoglou et al., 1994). In brief, samples were homogenized in the presence of $8 \mathrm{~mL}$ of $5 \mathrm{~g} / 100 \mathrm{~mL}$ aqueous trichloroacetic acid (Merck, Darmstadt, Germany) and $5 \mathrm{~mL}$ of $0.8 \mathrm{~g} / 100 \mathrm{~mL}$ butylated hydroxytoluene (Sigma Chemical Co, St. Louis, MO) in hexane, and the mixture was centrifuged. The top layer was discarded, and a $2.5 \mathrm{~mL}$ aliquot from the bottom layer was mixed with $1.5 \mathrm{~mL}$ of $0.8 \mathrm{~g} / 100 \mathrm{~mL}$ aqueous 2-thiobarbituric acid (Sigma Chemical Co, St. Louis, MO) and further incubated at $70{ }^{\circ} \mathrm{C}$ for $30 \mathrm{~min}$. Following incubation, the mixture was cooled under tap water and submitted to conventional spectrophotometry (Shimadzu, Model UV-160A, Tokyo, Japan) in the range of $400-650 \mathrm{~nm}$. Third-order derivative spectra were produced by digital differentiation of the normal spectra using a derivative wavelength difference setting of $21 \mathrm{~nm}$. The concentration of MDA in the analyzed samples was calculated on the basis of the height of the third-order derivative peak at $521.5 \mathrm{~nm}$ by referring to slope and intercept data of the computed least-squares fit of standard calibration curve prepared, using 1,1,3,3-tetraethoxypropane (Sigma Chemical Co, St. Louis, M.O., USA.).

For microbiological analysis, fillets ( $25 \mathrm{~g}$ ) were aseptically weighed, placed in sterile stomacher bags, wrapped and stored at $4{ }^{\circ} \mathrm{C}$ in the dark for 12 days. Sampling was carried out on day 0 and at 2-day intervals for up to 12 days of refrigerated storage. At each sampling day samples in stomacher bags were suspended in $225 \mathrm{~mL}$ sterile $0.1 \mathrm{~g} / 100 \mathrm{~g}$ peptone water (Oxoid, Unipath, Basingstone, UK), and homogenized in a stomacher (Lab Blender 400, Seward Medical Ltd, London, England) for $90 \mathrm{~s}$ at room temperature. Serial decimal dilutions were prepared in $0.1 \mathrm{~g} / 100 \mathrm{~g}$ peptone water and $1 \mathrm{~mL}$ of each diluent was poured in duplicate along with molten agar on plates utilizing the pour-plating technique. Bacterial counts were determined as follows: total viable count (TVC) on plate count agar (Oxoid), incubated at $25^{\circ} \mathrm{C}$ for $72 \mathrm{~h}$; lactic acid bacteria (LAB) on de Man, Rogosa, Sharpe (MRS) agar (Oxoid), overlaid with the same medium and incubated anaerobically at $25{ }^{\circ} \mathrm{C}$ for $96 \mathrm{~h}$; Enterobacteriaceae (ENB) on violet red bile dextrose 
(VRBD) agar (Oxoid) incubated at $37^{\circ} \mathrm{C}$ for $24 \mathrm{~h}$; psychrotrophic bacteria counts (PSY) on plate count agar (Oxoid), incubated at $7{ }^{\circ} \mathrm{C}$ for 10 days.

For the extraction of $\alpha$-tocopherol, muscle samples $(0.5 \mathrm{~g})$ were homogenized with $5 \mathrm{~mL}$ of a saturated methanolic solution of $\mathrm{KOH}$ in the presence of $100 \mu \mathrm{L}$ pyrocatechol (Merck, Darmstadt, Germany) solution $(200 \mathrm{mg} / \mathrm{mL})$, and then immersed in a waterbath at $80{ }^{\circ} \mathrm{C}$ for $15 \mathrm{~min}$ (Botsoglou et al., 1998). Following saponification, $5 \mathrm{~mL}$ hexane and $1 \mathrm{~mL}$ water were added, and the mixture was vortex-mixed and centrifuged at $2000 \mathrm{~g}$. An aliquot of the upper phase was evaporated to dryness to be further reconstituted in methanol and injected into the liquid chromatograph (Shimadzu, Model 6AV, Tokyo, Japan). Liquid chromatography was carried out, using a Nucleosil $\mathrm{C}_{18}, 5 \mathrm{~mm}, 250 \times 4.6 \mathrm{~mm}$ column (Reading, U.K.), and a mobile phase of methanol/water $(97: 3, \mathrm{v} / \mathrm{v})$ that was delivered to the system at a flowrate of $2 \mathrm{~mL} / \mathrm{min}$. A fluorimetric detector set at an excitation wavelength of $290 \mathrm{~nm}$ and an emission wavelength of $330 \mathrm{~nm}$ was used for monitoring column effluents. Detector signals were quantified on the basis of peak heights and a calibration curve using $\alpha$-tocopherol (Sigma Chemical Co, St. Louis, M.O., USA) as reference standard.

Each individual turkey within each group served as an experimental unit in the statistical analysis of all data. Data were subjected to a two-way analysis of variance (ANOVA) with treatment and storage as fixed effects in the general linear model of the SPSS 10.05 statistical package (SPSS Ltd., Woking, Surrey, UK). The homogeneity of the variances was tested by the Levene's test. When significant treatment effects were disclosed at the significance level of $\mathrm{P}<0.05$, the Tukey's test was applied in order to determine statistical differences between means.

\section{Results and Discussion}

At the completion of the study, average body weights $(4920 \pm 213 \mathrm{~g})$ and feed conversion ratios $(2.16$ $\pm 0.02)$ did not differ significantly $(\mathrm{P}>0.05)$ between groups, indicating that the incorporation of olive leaves or rosemary to the diets had no adverse influences on the growth rate of the turkeys.

Figure 1 shows that the extent of lipid oxidation in raw turkey breast fillets stored at $4{ }^{\circ} \mathrm{C}$ for up to 12 days varied with the storage time and the dietary treatment. Refrigerated storage increased the levels of malondialdehyde (MDA), the compound used as an index of lipid oxidation, the increase being higher for the CONT group. The T150 group presented MDA values that were significantly $(\mathrm{P}<0.05)$ lower than the

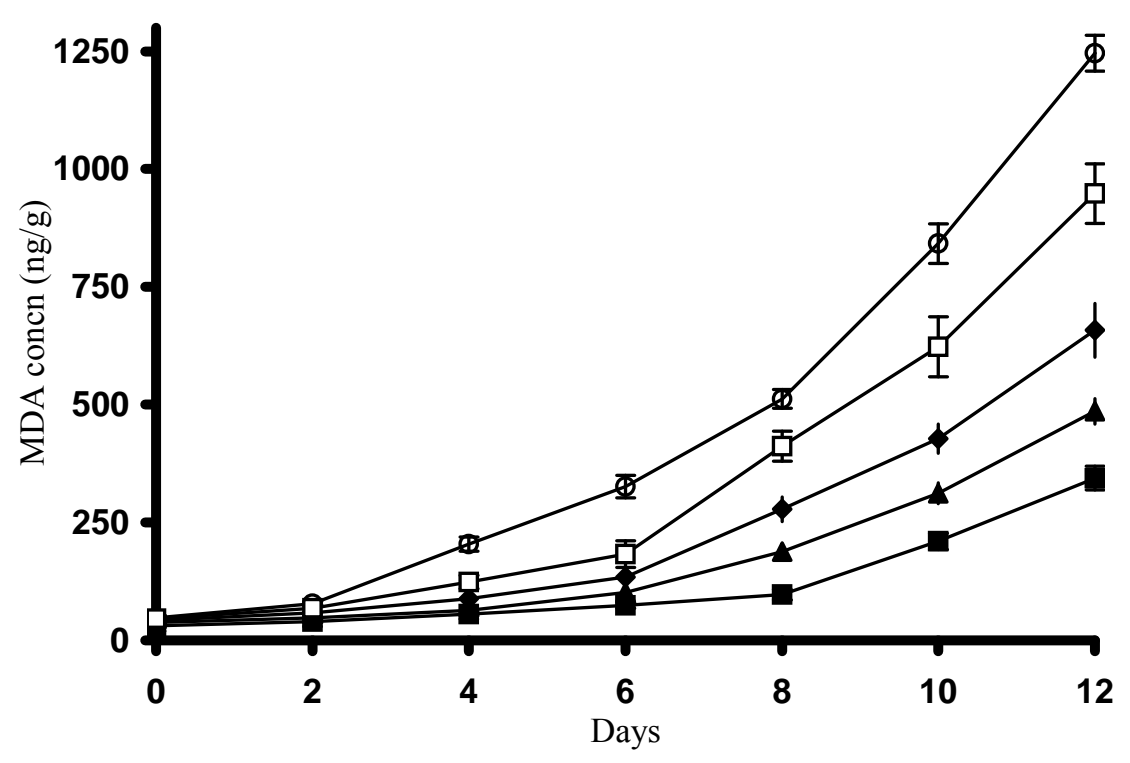

Figure 1 Effect of refrigerated storage on lipid oxidation of raw breast fillets as a function of storage time and diet; control diet (o), diet supplemented with $10 \mathrm{~g}$ rosemary $/ \mathrm{kg}$ feed (४), diet supplemented with $10 \mathrm{~g}$ olive leaves $/ \mathrm{kg}$ feed $(\boldsymbol{\Delta})$, diet supplemented with $150 \mathrm{mg} \alpha$-tocopheryl acetate/ $\mathrm{kg}$ feed (口), diet supplemented with $300 \mathrm{mg} \alpha$-tocopheryl acetate $/ \mathrm{kg}$ feed (๘). All data points represent mean values accompanied by standard deviation bars some of which, however, lie within the data point regions. 
CONT group but higher $(\mathrm{P}<0.05)$ than the ROS group at all time points of refrigerated storage. On the other hand, the OL group had MDA values that were significantly $(\mathrm{P}<0.05)$ lower than the ROS group but higher $(\mathrm{P}<0.05)$ than the T300 group at all time points of refrigerated storage.

These results indicate that the incorporation of $\alpha$-tocopheryl acetate at a level of $150 \mathrm{mg} / \mathrm{kg}$ into the turkey diet delayed lipid oxidation as compared to the control $(\mathrm{P}<0.05)$. Rosemary incorporation was more effective $(\mathrm{P}<0.05)$ in delaying lipid oxidation compared to $\alpha$-tocopheryl acetate at $150 \mathrm{mg} / \mathrm{kg}$, but less effective $(\mathrm{P}<0.05)$ as compared to the incorporation of olive leaves. In turn, olive leaves delayed lipid oxidation at an extent lower than that of $\alpha$-tocopheryl acetate at a level of $300 \mathrm{mg} / \mathrm{kg}$ feed.

The inhibition of lipid oxidation in the breast meat after diet supplementation with olive leaves or rosemary is probably the result of various constituents with antioxidant activity that entered the circulatory system, and distributed and retained in turkey tissues. Even though, in the present experiment, the active constituents of olive leaves and rosemary could not be individually quantified since their bioavailability could not be demonstrated directly due to the lack of adequate analytical methodology and equipment, the amount of total phenolics and their antioxidant activity toward the ABTS radical cation were determined.

Chemical analysis showed that the total phenol content of olive leaves was $23.8 \mathrm{mg}$ of gallic acid equivalents $/ \mathrm{g}$, whereas the antioxidant activity expressed in TEAC values was $1.52 \mathrm{mM} / \mathrm{g}$. This TEAC value compares well with that reported in a previous study where it was further found that olive leaves had an antioxidant activity higher than vitamins $\mathrm{C}$ and $\mathrm{E}$, due to a synergy between flavonoids, oleuropeosides and substituted phenols (Benavente-Garcia et al., 2000). Analysis results also showed that the total phenol content of rosemary was $29.4 \mathrm{mg}$ of gallic acid equivalents/g, whereas its antioxidant activity expressed in TEAC values was $0.95 \mathrm{mM}$ trolox equivalents/g.

The results obtained in this study are difficult to compare with previous reports since there have not been specific in vivo studies where both olive leaves and rosemary were supplemented. Supplementation of turkey diets with only rosemary at the level of $10 \mathrm{~g} / \mathrm{kg}$, although effective in delaying lipid oxidation in turkey tissues, has been reported to be inferior to the dietary supplementation of $300 \mathrm{mg} \alpha$-tocopheryl acetate $/ \mathrm{kg}$ feed (Botsoglou et al., 2007). Other in vitro experiments with rosemary showed that the antioxidant activity of rosemary extracts was lower, comparable, or even higher than that of $\alpha$-tocopherol (Kuzmenko et al., 1999). On the other hand, in vivo studies with olive leaves components demonstrated that hydroxytyrosol, administered to rats as the only bioactive component of an olive mill waste, was able to increase plasma antioxidant capacity (Visioli et al., 2001), whereas it could also protect human erythrocytes against oxidation (Manna et al., 1999).

Moreover, in vitro experiments showed that olive leaf extracts and their main components, oleuropein and hydroxytyrosol, were much more effective than BHT or vitamin E in limiting the oxidation of methyl linoleate in model systems (Le Tutour \& Guedon, 1992). The use of olive leaf juice has also been found suitable for extending the stability of sunflower oil during heating (Farag et al., 2007).

Considering that the larger the amount of $\alpha$-tocopherol in tissues the better the protection against oxidative attack, samples from all groups were analyzed for their $\alpha$-tocopherol content at day 0 of refrigerated storage. Mean $\alpha$-tocopherol level in the CONT group was found to be $0.96 \pm 0.22 \mu \mathrm{g} / \mathrm{g}$ tissue. Supplementing the diets with olive leaves or rosemary at $10 \mathrm{~g} / \mathrm{kg}$ changed the levels of $\alpha$-tocopherol in fillets to values of $0.86 \pm 0.32$ and $1.12 \pm 0.38 \mu \mathrm{g} / \mathrm{g}$, respectively. These values did not differ $(\mathrm{P}>0.05)$ among each other or from the CONT group. Supplementing the diet with 150 and $300 \mathrm{mg} \alpha$-tocopheryl acetate $/ \mathrm{kg}$ increased the levels of $\alpha$-tocopherol in the fillets to $1.92 \pm 0.44$ and $2.72 \pm 0.26 \mu \mathrm{g} / \mathrm{g}$, respectively. Values of $\alpha$-tocopherol for the CONT and TOC breast samples compare well with literature data. However, the concentrations of $\alpha$-tocopherol are low compared to that in chickens, substantiating the fact that $\alpha$-tocopherol is not efficiently absorbed and deposited in the cell membranes of turkeys (Botsoglou et al., 2003; Papageorgiou et al., 2003).

The shelf life of stored muscle food is associated with the extent and type of microbial growth that may occur during the additional time of product storage. Therefore, TVC, LAB, ENB and PSY bacteria that constitute a major cause of poultry meat spoilage during refrigerated storage were determined. Figure 2 shows that TVC, LAB, ENB and PSY bacterial counts were all significantly increased $(\mathrm{P}<0.05)$ in samples of all groups as the refrigerated storage period progressed. The CONT, T150 and T300 groups presented TVC, LAB, ENB and PSY counts that did not differ $(\mathrm{P}>0.05)$ among each other during the whole storage period. However, the olive leaves- and rosemary-supplemented groups presented bacterial counts that were significantly lower $(\mathrm{P}<0.05)$ than the CONT, T150 and T300 groups, at day 2 of storage period and 
thereafter. During this period, ROS group presented TVC, LAB, ENB and PSY counts that were significantly higher $(\mathrm{P}<0.05)$ than the OL group.

TVC

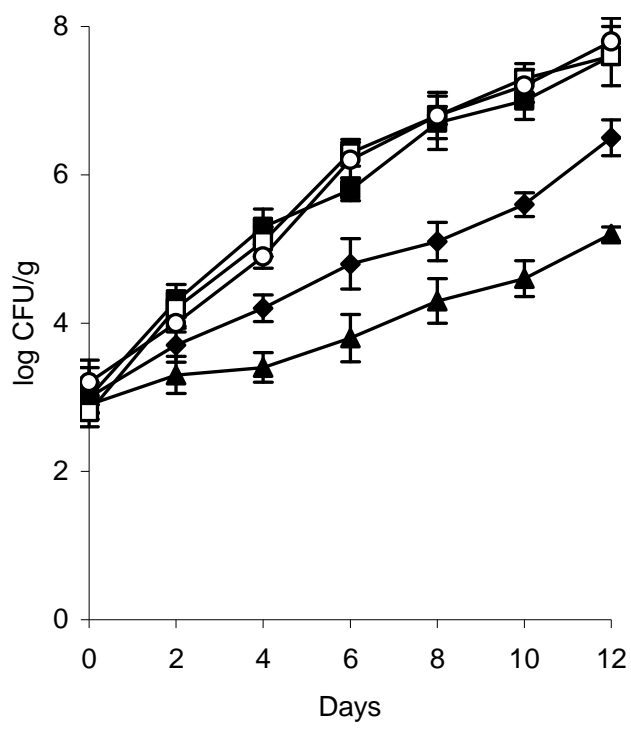

ENB

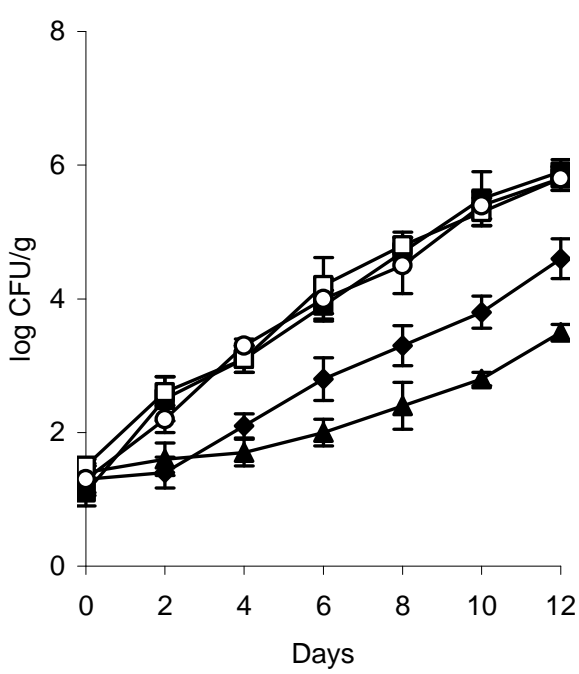

LAB

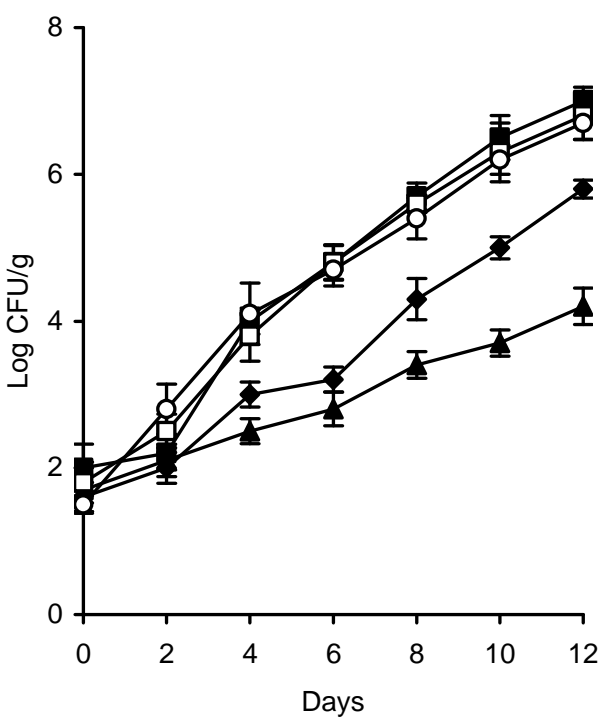

PSY

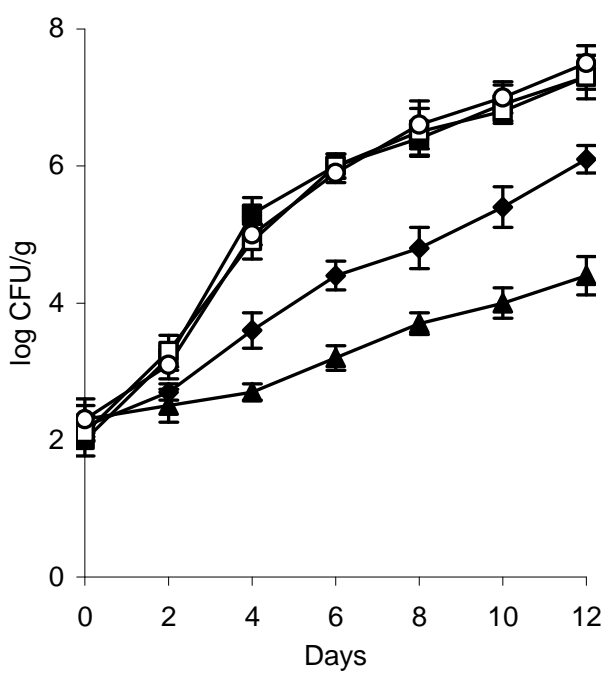

Figure 2 Changes in total viable counts (TVC), lactic acid bacteria (LAB), Enterobacteriaceae (ENB) and psychrotrophic bacteria (PSY) in turkey breast fillets stored at $4{ }^{\circ} \mathrm{C}$ in the dark for up to 12 days: Control diet (o), diet supplemented with $10 \mathrm{~g}$ rosemary $/ \mathrm{kg}$ feed $(\diamond)$, diet supplemented with $10 \mathrm{~g}$ olive leaves $/ \mathrm{kg}$ feed ( $\boldsymbol{\Delta}$ ), diet supplemented with $150 \mathrm{mg} \alpha$-tocopheryl acetate/kg feed ( $\square$ ), diet supplemented with $300 \mathrm{mg} \alpha$ tocopheryl acetate $/ \mathrm{kg}$ feed ( $\boldsymbol{\square}$ ). All data points represent mean values accompanied by standard deviation bars some of which, however, lie within the data point regions. 
At day 12 of storage, mean levels of TVC counts in the CONT, T150 and T300 groups were in the range of $7.6-7.8 \log$ CFU/g, whereas in the ROS and OL groups at 6.5 and $5.2 \log$ CFU/g, respectively. At this day of storage, mean levels of LAB counts in the CONT, T150 and T300 groups were in the range of 6.7 - $7.0 \log \mathrm{CFU} / \mathrm{g}$, whereas in the ROS and OL groups at 5.8 and $4.2 \log \mathrm{CFU} / \mathrm{g}$, respectively. At the same time, mean levels of ENB counts in the CONT, T150 and T300 groups were in the range of $5.8-5.9 \log$ $\mathrm{CFU} / \mathrm{g}$, whereas in ROS and OL10 groups at 4.6 and $3.5 \mathrm{log} \mathrm{CFU} / \mathrm{g}$, respectively. On the same day, mean levels of PSY counts in the CONT, T150 and T300 groups were in the range of $7.3-7.5 \log \mathrm{CFU} / \mathrm{g}$, whereas in the ROS and OL groups counts were at 6.1 and $4.4 \log \mathrm{CFU} / \mathrm{g}$, respectively.

These results indicate that the dietary supplementation of both olive leaves and rosemary at $10 \mathrm{~g} / \mathrm{kg}$ feed exerted an inhibitory activity on the growth of TVC, LAB, ENB and PSY bacteria in the stored turkey breast samples. This is in agreement with previous reports on the in vitro antimicrobial activity of olive leaves and its constituents (Capasso et al., 1995; Markin et al., 2002).

Olive leaf extracts and its constituents have shown an inhibitory effect against psychrotrophic bacteria such as B. subtilis, Pseudomonas spp. and Proteus vulgaris (Kubo et al., 1995; Markin et al., 2002). Oleuropein, the main active component of olive leaves, has been reported to act against lactic acid bacteria such as Lactobacillus plantarum (Ruiz-Barba et al., 1991) and food-borne pathogens such as Salmonella enteriditis (Tassou \& Nychas, 1995) and Bacillus cereus (Tassou et al., 1991). In addition, oleuropein showed an inhibitory effect on the growth and enterotoxin production by Staphylococcus aureus (Tassou \& Nychas, 1994), whereas both hydroxytyrosol and oleuropein exhibited an inhibitory effect against several bacterial strains (ATCC) such as Staphylococcus aureus, Vibrio parahaemolyticus or Salmonella spp., that are causal agents of intestinal or respiratory tract infections in humans (Bisignano et al., 2001).

The results of this study also support previous reports on the in vitro antimicrobial activity of rosemary and its extracts. The in vitro antimicrobial activity of the essential oil of rosemary against several foodborne pathogens such as Salmonella enteritidis, Salmonella typhimurium, Campylobacter jejuni, Escherichia coli O157:H7, Stapylococcus aureus, Bacillus subtilis, Pseudomonas aeruginosa and Aeromonas hydrophila has been reported frequently (Smith-Palmer et al., 1998; Ahn et al., 2004). The essential oil of rosemary has been found to be bacteriostatic against strains of Listeria monocytogenes at concentrations of $0.02-0.05 \%$ (Smith-Palmer et al., 1998), bacteriocidal at concentrations of $0.1-0.5 \%$ (Pandit \& Shelef, 1994; SmithPalmer et al., 1998) and sporostatic against Bacillus cereus at $170 \mathrm{mg} / \mathrm{kg}$ (Chaibi et al., 1997) in culture media. It has also been reported to be effective against several enterobacteria including E. coli, Streptococcus faecalis, Alcaligenes faecalis (Barrata et al., 1998; Smith-Palmer et al., 1998), Shigella spp. (Bagamboula et al., 2003), certain lactic acid bacteria including Lactobacillus plantarum, Leuconostoc cremoris and Lactobacillus carvatus (Quattara et al., 1997) and six psychrothrophic bacteria of meat spoilage including Pseudomonas fluorescens, Serratia liquefaciens, Brochothrix thermoshacta, Carnobacterium piscicola, Lactobacillus carvatus and Lactobacillus sake at levels of $0.01-0.1 \%$ in culture broths (Quattara et al., 1997). Moreover, the essential oil of rosemary sprayed on beef steaks at a level of $1000 \mathrm{mg} / \mathrm{kg}$ reduced the microbial growth of psychrotrophic bacteria during refrigerated storage under a modified atmosphere (Djenane et al., 2003), whereas its direct addition to ground beef at a level of $1 \%$ resulted in reduction of Salmonella typhimurium, Escherichia coli $\mathrm{O} 157: \mathrm{H} 7$ and Listeria monocytogenes populations at about $1 \mathrm{log}$ $\mathrm{CFU} / \mathrm{g}$ after refrigerated storage for nine days (Ahn et al., 2004).

The results of this study also showed that the dietary supplementation of 150 and $300 \mathrm{mg} \alpha$-tocopheryl acetate $/ \mathrm{kg}$ feed exerted no inhibitory effect on TVC, LAB, ENB and PSY bacterial counts in breast samples stored for up to 12 days. This is in line with previous studies, reporting no effect of dietary vitamin $\mathrm{E}$ on aerobic plate counts in raw pork (Cannon et al., 1995) and beef meat (Chan et al., 1995). However, other workers (Asghar et al., 1991) reported that bacterial growth was greater in chops from pigs fed diets with supplemental vitamin E, which had lower drip losses. This difference in bacterial counts was ascribed to potentially higher water activity or reduced antimicrobial activity due to lack of lipid oxidation products because of the action of vitamin E.

At day 10 and thereafter, the CONT group showed initial signs of spoilage with the development of off-flavours and indication of slime formation; by this time, TVC counts of these samples were about $7 \log$ CFU/g. This is in agreement with Sofos et al. (2000), who reported that meat spoilage is visible when bacteria counts reached about $7 \mathrm{log} \mathrm{CFU} / \mathrm{g}$. Other workers found similar changes in microbial growth and time for the onset of spoilage in turkey fillets under refrigerated storage (Mano et al., 2000). However, T150 and T300 groups did not show initial signs of spoilage, although samples presented bacterial counts similar 
to the CONT group. No signs of spoilage were also noticed for the other dietary groups up to the end of the storage period. This retardation on visible signs of spoilage of these samples might endanger consumers' health due to increased numbers of bacterial counts.

\section{Conclusion}

Results showed that the incorporation of olive leaves and rosemary in turkey diets delayed lipid oxidation in raw breast fillets during refrigerated storage for up to 12 days. The incorporation of olive leaves at the level of $10 \mathrm{~g} / \mathrm{kg}$ was found to be more effective in delaying lipid oxidation than rosemary, but inferior to the dietary supplementation of $300 \mathrm{mg} \alpha$-tocopheryl acetate/kg. Both olive leaves and rosemary also exerted an inhibitory effect on the growth of TVC, LAB, ENB and PSY bacteria in breast samples during storage. The rate of inhibition against microbial growth was higher in the case of olive leaves and lower in the case of rosemary. The dietary supplemented $\alpha$-tocopheryl acetate did not show such an antimicrobial effect. Therefore, if shown clinically to be safe and having beneficial effects in vivo, rosemary and particularly olive leaves might be utilized in novel applications as nutritional supplements or as functional food components.

\section{References}

Ahn, J., Grun, I. \& Mustapha, A., 2004. Antimicrobial and antioxidant activities of natural extracts in vitro and in ground beef. J. Food Prot. 67, 148-155.

Asghar, A., Gray, J.I., Booren, A.M., Gomaa, E., Abouzied, M., Miller, E. \& Buckley, D.J., 1991. Effects of supranutritional dietary vitamin E levels on subcellular deposition of $\alpha$-tocopherol in the muscle and on pork quality. J. Sci. Food Agric. 57, 31-41.

Bagamboula, C.F., Uyttendaele, M. \& Debevere, J., 2003. Antimicrobial effect of spices and herbs on Shigella sonnei and Shigella flexneri. J. Food Prot. 66, 668-673.

Barrata, M.T., Dorman, D.J.H., Deans, S.G., Biondi, D.M. \& Roberto, G., 1998. Chemical composition, antimicrobial and antioxidative activity of laurel, sage, rosemary, oregano, coliander essential oils. J. Ess. Oil Res.10, 618-627.

Benavente-Garcia, O., Castillo, J., Lorente, J., Ortuno, A. \& Del Rio, J.A., 2000. Antioxidant activity of phenolics extracted from Olea europea L. leaves. Food Chem. 68, 457-462.

Bisignano, G., Lagana, M.G., Trombetta, D., Arena, S., Nostro, A., Uccella, N., Mazzanti, G. \& Saija, A., 2001. In vitro antibacterial activity of some aliphatic aldehydes from Olea europea L. FEMS Microbiol Lett.198, 9-13.

Botsoglou, N.A., Fletouris, D.J., Papageorgiou, G.E., Vassilopoulos, V.N., Mantis, A.J. \& Trakatellis, A.G., 1994. A rapid, sensitive, and specific thiobarbituric acid method for measuring lipid peroxidation in animal tissues, food, and feedstuff samples. J. Agric. Food Chem. 42, 1931-1937.

Botsoglou, N.A., Fletouris, D.J., Psomas, I. \& Mantis, A., 1998. Rapid gas chromatographic method for simultaneous determination of cholesterol and tocopherol in eggs. J. AOAC Int. 81, 1177-1183.

Botsoglou, N.A., Grigoropoulou, S.H., Botsoglou, E., Govaris, A. \& Papageorgiou, G., 2003. The effects of dietary oregano essential oil and $\alpha$-tocopheryl acetate on lipid oxidation in raw and cooked turkey during refrigerated storage. Meat Sci. 65, 1193-1200.

Botsoglou, N.A., Govaris, A., Giannenas, I., Botsoglou, E. \& Papageorgiou, G., 2007. The incorporation of dehydrated rosemary leaves in the rations of turkeys and their impact on the oxidative stability of the produced raw and cooked meat. Int. J. Food Sci. Nutr. 58, 312-320.

Cannon, J.E., Morgan, J.B., Schmidt, G.R., Delmore, R.J., Sofos, J.N., Smith, G.C. \& Williams, S.N., 1995. Vacuum-packaged precooked pork from hogs fed supplemental vitamin E: Chemical self-life and sensory properties. J. Food Sci. 60, 1179-1182.

Capasso, R., Evidente, A., Schivo, L., Orru, G. \& Marciallis, M.A., 1995. Antibacterial polyphenols from olive oil mill waste waters. J. Appl. Bacteriol. 79, 393-398.

Chaibi, A., Ababouch, L.H., Belasri, K., Boucetta, S. \& Busta, F.F., 1997. Inhibition of germination and vegetative growth of Bacillus cereus $\mathrm{T}$ and Clostridium botulinum 62A spores by essential oils. Food Microbiol. 14, 161-174.

Chan, W.K.M., Hakkarainen, K., Faustman, C., Schaefer, D.C., Scheller, K.K. \& Liu, Q., 1995. Effect of endogenous $\alpha$-tocopherol on the relationship between microbial growth and color stability in beef. J. Food Sci. 42, 151-155. 
Committee on Care and Use of Laboratory Animals, 1996. Guide for the care and use of laboratory animals. Institute of laboratory Animal Resources, Commission on Life Sciences. National Research Council, National Academy Press, USA., Washington, D.C., USA.

Cuvelier, M., Richard, H. \& Berset, C., 1996. Antioxidative activity and phenolic composition of pilot-plant and commercial extracts of sage and rosemary. J. Am. Oil Chem. Soc. 73, 645-652.

Djenane, D., Sanchez-Escalante, A., Beltran, J.A. \& Roncales, P., 2003. Extension of the shelf life beefsteaks packaged in a modified atmosphere by treatment with rosemary and displayed under UVfree lighting. Meat Sci. 64, 417-426.

Farag, R.S., Mahmoud, E.A. \& Basuny, A.M., 2007. Use of olive leaf juice as a natural antioxidant for the stability of sunflower oil during heating. Int. J. Food Sci. Technol. 42, 107-115.

Govaris, A., Florou-Paneri, P., Botsoglou, E., Giannenas, I., Amvrosiadis, I. \& Botsoglou, N., 2007. The inhibitory potential of feed supplementation with rosemary and/or a-tocopheryl acetate on microbial growth and lipid oxidation of turkey breast during refrigerated storage, Food Sci. Technol. 40, 331-337.

Ibanez, E., Kubatova, A., Senorans, F.J, Cavero, S., Reglero, G. \& Hawthorn, S.B., 2003. Subcritical water extraction of antioxidant compounds from rosemary plants. J. Agric. Food Chem. 50, 3512-3517.

Kubo, A., Lunde, C.S. \& Kubo, I., 1995. Antimicrobial activity of the olive oil flavor compound. J. Agric. Food Chem. 43, 1629-1633.

Kuzmenko, A.I., Morozova, R.P., Nikolenko, I.A., Donchenko, G.V., Richheimer, S.L. \& Bailey, D.T., 1999. Chemiluminiscence determination of the in vivo and in vitro antioxidant activity of RoseOx ${ }^{\circledR}$ and carnosic acid. J. Photochem. Photobiol. 48, 63-67.

Le Tutour, B. \& Guedon, D., 1992. Antioxidative activities of Olea europea leaves and related phenolic compounds. Phytochem. 31, 1173-1178.

Manna, C., Galletti, P., Cucciolla, V., Montedoro, G. \& Zappia, V., 1999. Olive oil hydroxytyrosol protects human erythrocytes against oxidative damage. J. Nutr. Biochem. 10, 159-165.

Mano, S.B., Ordoňez, J.A. \& Garcia de Fernando, G.D., 2000. Growth/survival of natural flora and Aeromonas Hydrophila on refrigerated uncooked pork and turkey packaged in modified atmospheres. Food Microbiol. 17, 657-672.

Markin, D., Duek, L. \& Berdicevsky, I., 2002. In vitro antimicrobial activity of olive leaves. Mycoses 46, 132-136.

Martinez-Tome, M., Jimenez, A., Ruggieri, S., Frega, N., Strabbioli, R. \& Murcia, A., 2001. Antioxidant properties of Mediterranean spices compared with common food additives. J. Food Prot. 64, 1412-1419.

Offord, E., Guillot, F., Aeschbach, R., Loliger, J. \& Pfeifer, A., 1997. Antioxidant and biological properties of rosemary components: Implications for food and health. In: Natural Antioxidants. Chemistry, Health Effects and Applications. Ed. Shahidi, F., Washington, AOCS, Press. pp. 88-96.

Quattara, B., Simard, R.E., Holley, R.A., Piete, G.J.P. \& Begin, A., 1997. Antibacterial activity of selected fatty acids and essential oils against six meat spoilage organisms. Int. J. Food Microbiol. 37, $155-162$.

Packer, J.E. \& Kagan, V.E., 1993. Vitamin E: The antioxidant harvesting center of membranes and lipoproteins. In: Vitamin E in Health and Disease. Eds Packer, L. \& Fuchs, J., New York, Marcel Dekker. pp. 179-192.

Pandit, V.A. \& Shelef, L.A., 1994. Sensitivity of Listeria monocytogenes to rosemary (Rosmarinus officinalis L.). Food Microbiol. 11, 57-63.

Papageorgiou, G., Botsoglou, N.A., Govaris, A., Giannenas, I., Iliadis, S. \& Botsoglou, E., 2003. Effect of oregano oil and $\alpha$-tocopheryl acetate dietary supplementation on iron-induced lipid oxidation of turkey breast, thigh, liver and heart tissues. J. Anim. Physiol. Anim. Nutr. 87, 1-12.

Re, R., Pellegrini, N., Proteggente, A., Pankala, A., Yang, M. \& Rice-Evans, C., 1999. Antioxidant activity applying an improved ABTS radical cation decolorization assay. Free Rad. Biol. Med. 26, 1231-1237.

Richheimer, S., Bernart, M., King, G., Kent, C. \& Bailey, D., 1996. Antioxidant activity of lipid-soluble phenolic diterpenes from rosemary. J. Am. Chem. Soc. 73, 507-514.

Ruiz-Barba, J.L., Garrido-Fernadez, A. \& Jimenez-Diaz, R., 1991. Bactericidal action of oleuropein extracted from green olives against Lactobacillus plantarum. Lett. Appl. Microbiol. 12, 65-68. 
Ryan, D., Antolovich, M., Prenzler, P., Robards, K. \& Lavee, S., 2002. Biotransformations of phenolic compounds in Olea europea L. Sci. Horticult. 92, 147-176.

Singleton, V.L., Orthofer, R. \& Lamuela-Raventos, R.M., 1999. Analysis of total phenols and other oxidation substrates and antioxidants by means of the Follin-Ciocalteau reagent. Methods Enzymol. 299, 152-178.

Smith-Palmer, A., Stewart, J. \& Fyfe, L., 1998. Antimicrobial properties of plant essential oils and essences against five important food-borne pathogens. Lett. Appl. Microbiol. 26, 118-122.

Tassou, S.C. \& Nychas, G.J., 1994. Inhibition of Staphylococcus aureusby olive phenolics in broth and in a model food system. J. Food Prot. 57, 120-124.

Tassou, S.C. \& Nychas, G.J., 1995. Inhibition of Salmonella enteriditis by oleuropein in broth and in model food system. Lett. Appl. Microbiol. 20, 120-124.

Tassou, S.C., Nychas, G.J. \& Board, R.G., 1991. Effect of phenolic compounds and oleuropein on germination of Bacillus cereus T spores. Biotechnol. Appl. Biochem. 13, 231-237.

Vercellotti, J.R., St. Angelo, A.J. \& Spanier, A.M., 1992. Lipid oxidation in foods, an overview. In: Lipid Oxidation in Food. Ed. St. Angelo. A.J., Washington, D.C., American Chemical Society Press. pp. 112-145.

Visioli, F., Bellomo, G., Montedoro, G. \& Galli, C.V., 1995. Low density lipoprotein oxidation is inhibited in vitro by olive constituents. Atherosclerosis 117, 25-32.

Visioli, F., Caruso, D., Plasmati, E., Patelli, R., Mulinacci, N. \& Romani, A., 2001. Hydroxytyrosol, as a component of olive meal waste water, is dose-dependently abosorbed and increases the antioxidant capacity of rat plasma. Free Rad. Res. 34, 301-305. 